\section{Endoscopic ultrasound-guided drainage of giant liver abscess associated with transgastric migration of a self-expandable metallic stent}
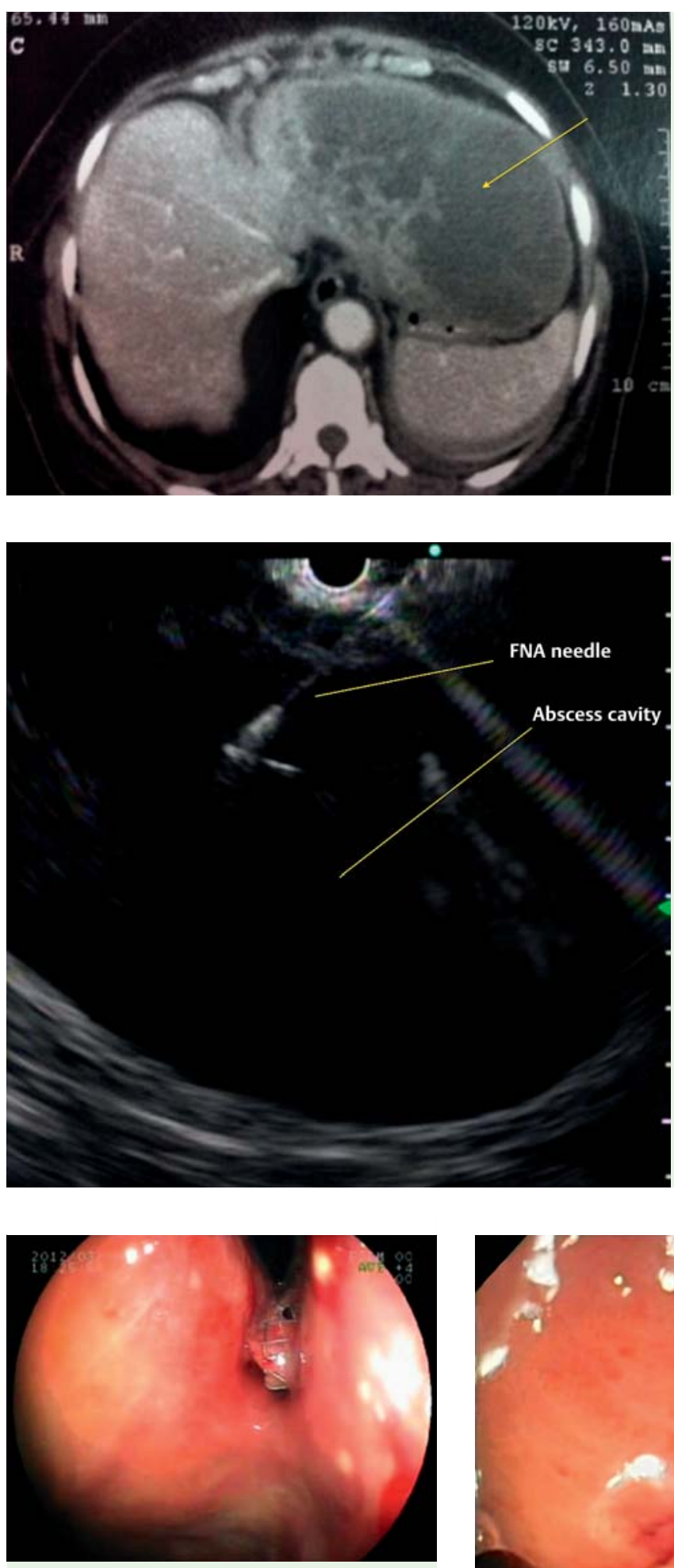

Fig. 3 Endoscopic view of the self-expandable metallic stent (SEMS).
Fig. 1 Computer tomography (CT) scan showing a giant liver abscess in a 73-year-old woman with abdominal pain and fever.

Fig. 2 Endoscopic ultrasound (EUS)-guided puncture of the liver abscess. FNA, fine needle aspiration.

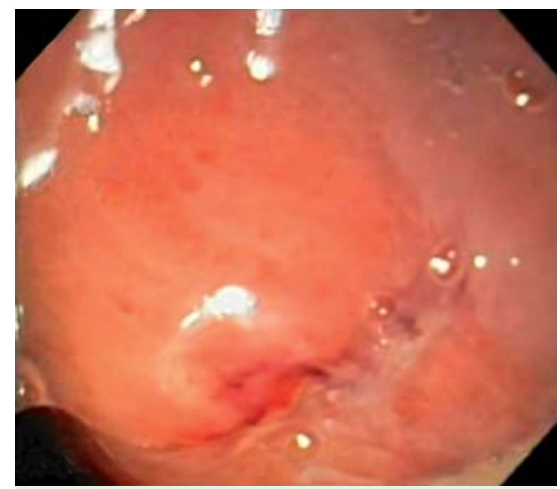

Fig. 4 Endoscopic view of the conduit without the SEMS (migrated).
Liver abscesses are usually drained percutaneously and if drainage is inadequate, surgery may be necessary [1]. Successful endoscopic ultrasound (EUS)-guided drainage has been described for abscesses located in the pancreas, pelvis, liver, and subphrenic space [2-4]. We report the first case of EUS-guided drainage of an abscess in the left lobe of liver in a patient with pancreatic tumor, using a self-expanding metallic stent (SEMS).

A 73-year-old woman was admitted with abdominal pain and fever. Abdominal computed tomography (CT) showed a hypodense mass in the pancreas, measuring $9.7 \times 9.3 \mathrm{~cm}$ ( $\bullet$ Fig. 1 ). After the patient had given informed consent, we carried out pancreatic fine needle puncture with EUS-guided drainage of the liver abscess ( $\bullet$ Fig. 2). The liver abscess was visualized using a therapeutic linear EUS device (GF-UCT160; Olympus, Tokyo, Japan) and punctured with a 19-gauge needle (EUSN-19-T; Cook Endoscopy, Winston-Salem, North Carolina, USA) via a transgastric approach. A 480-cm long, 0.035 -inch guide wire was inserted and the puncture needle was withdrawn. A cystotome (Boston Scientific, Natick, Massachusetts, USA) was inserted over the guide wire to traverse the gastric wall. The cystotome was then withdrawn, leaving the guide wire within the abscess cavity. Transgastric drainage was carried out using a $60 \times 10 \mathrm{~mm}$, partially covered SEMS (Boston Scientific, Natick, Massachusetts, USA) over the guide wire ( $\bullet$ Fig.3). There were no complications. At 2 weeks after the procedure, EUS revealed a reduction in the size of the liver abscess and intra-abscess stent migration ( $\bullet$ Fig.4). A guide wire was inserted in the puncture site using a catheter (MicroKnife XL, Boston Scientific, Natick, Massachusetts, USA) to cannulate the SEMS ( Fig.5). Stent cannulation was confirmed using radiography and EUS. The catheter was withdrawn and a 10-Fr double pigtail plastic stent was inserted inside the SEMS to preserve the drainage channel ( Fig.6). The patient was prescribed antibiotics and after 2 weeks, CT showed a reduction of the collection. The liver abscess resolved completely by 8 weeks and histological examination of the pancreatic lesion revealed pancreatic stromal tumor. The patient had an uneventful follow-up.

Endoscopy_UCTN_Code_TTT_1AS_2AD

Competing interests: None 


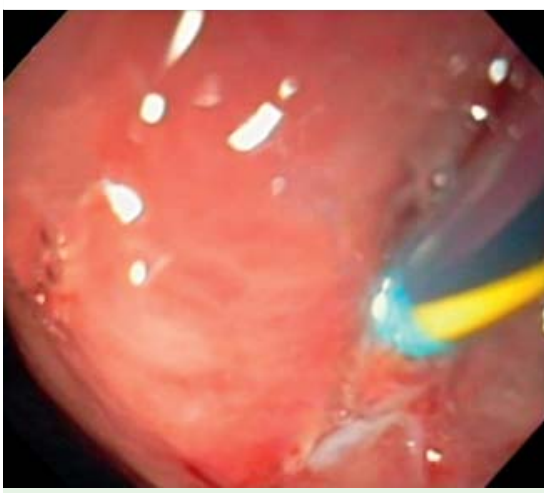

Fig. 5 Recannulation attempt to recover the migrated stent.

\section{B. F. Medrado, F. O. A. A. Carneiro, T. G. Vilaça, T. S. Gouveia,} M. S. V. Frazão, E. G. H. de Moura, P. Sakai, J. P. Otoch, E. L. A. Artifon

Gastrointestinal Endoscopy Unit - Gastroenterology Department, University of São Paulo - School of Medicine, São Paulo, Brazil

\section{References}

1 Chung YFA, Tan YM, Lui HF et al. Management of pyogenic liver abscesses - percutaneous or open drainage? Singapore Med J 2007; 48: 1158-1165, quiz 1165

2 Seewald S, Imazu H, Omar S et al. EUS-guided drainage of hepatic abscess. Gastrointest Endosc 2005; 61: 495 - 498

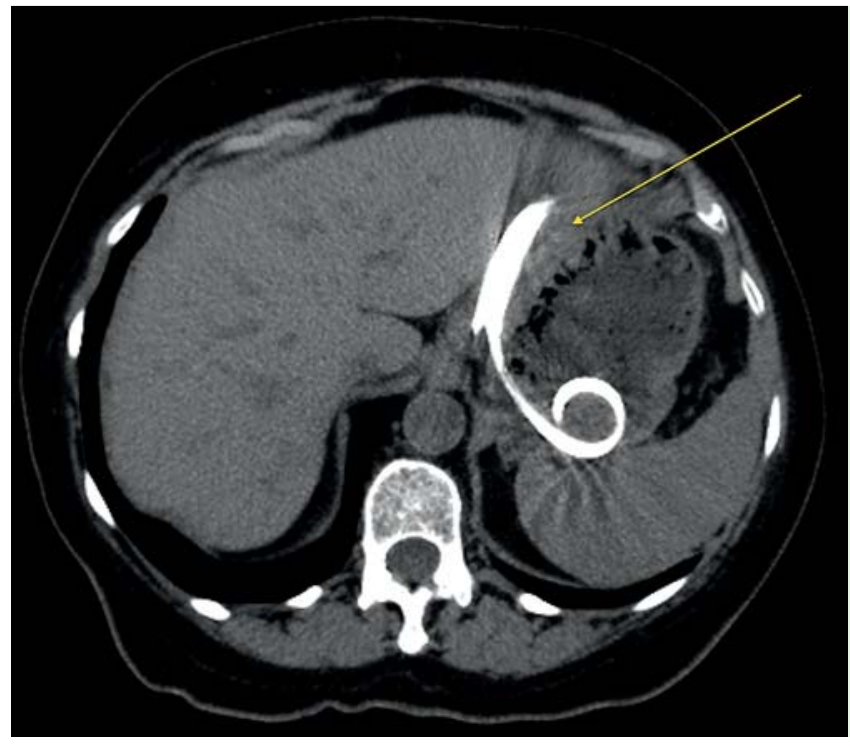

Fig. 6 Computer tomography $(\mathrm{CT})$ view of the double pigtail within the self-expandable metallic stent (SEMS), associated with resolution of the liver abscess.

3 Itoi T, Ang TL, Seewald $S$ et al. Endoscopic ultrasonography-guided drainage for tuberculous liver abscess drainage. Dig Endosc 2011; 23: $158-161$

4 Fernandez-Urien I, Vila JJ, Jimenez FJ. Endoscopic ultrasound-guided drainage of pelvic collections and abscesses. World J Gastrointest Endosc 2010; 2: 223-227

Bibliography

DOI http://dx.doi.org/

10.1055/s-0033-1344128

Endoscopy 2013; 45: E331-E332

(c) Georg Thieme Verlag KG

Stuttgart · New York

ISSN 0013-726X
Corresponding author

\section{E. L. A. Artifon}

University of São Paulo School of Medicine

Dr. Enéas de Carvalho Aguiar Avenue 255 - Cerqueira César, 05403-000 São Paulo

Brazil

Fax: +5511-2661-7579

eartifon@hotmail.com 